Original Article

Artigo Original

Adriana Pereira Defina Iqueda ${ }^{1}$

Hilton Ricz'

Telma Kioko Takeshita ${ }^{1}$

Nathália dos Reis ${ }^{1}$

Lílian Aguiar-Ricz'

Keywords

Laryngectomy

Speech, alaryngeal

Voice quality

Laryngeal neoplasms

Rehabilitation

Descritores

Laringectomia

Voz alaríngea

Qualidade da voz

Neoplasias laríngeas

Reabilitação
Correspondence address:

Hilton Ricz

Faculdade de Medicina de Ribeirão Preto, USP

Departamento de Oftalmologia, Otorrinolaringologia e Cirurgia de Cabeça e Pescoço

Avenida Bandeirantes, 3900, Monte Alegre, Ribeirão Preto (SP), Brasil, CEP: $14048-900$.

E-mail: hricz@fmrp.usp.br

\section{Nasalance and nasality of tracheoesophageal speech in total laryngectomee}

\author{
Nasalância e nasalidade da voz traqueosofágica \\ em laringectomizados totais
}

\begin{abstract}
Objectives: The objective of this study was to determine the rates of nasalance for total laryngectomized users of a tracheoesophageal voice prosthesis and correlate them with the findings of auditory-perceptual assessment of nasality. Methods: In this study, 25 total laryngectomized users, including 20 men and five women, with a mean age of 63 years old participated. All the participants had a tracheoesophageal voice prosthesis and underwent treatment for the rehabilitation of tracheoesophageal communication. These patients were submitted to nasalance assessment using nasometry and auditory-perceptual evaluation of nasality and were rated by trained speech therapists. Results: The nasalance values obtained for nasal (59.92\%) and oral (18.64\%) sentences were within the normal limits for laryngeal speakers of Brazilian Portuguese language. It was possible to observe the presence of nasality in nasal sentences and its absence in oral sentences among most speakers. Specificity was found to be $100 \%$ for nasal sentences and sensitivity was $100 \%$ for oral sentences. It was not possible to calculate these values for the oral sentences. Conclusions: Total laryngectomized patients with tracheoesophageal voice prostheses have adequate vocal nasality compatible with nasometry rates.
\end{abstract}

\section{RESUMO}

Objetivos: Determinar os índices de nasalância de laringectomizados totais usuários de prótese traqueoesofágica e correlacioná-los com os achados da avaliação perceptivo-auditiva da nasalidade. Métodos: Participaram do estudo 25 laringectomizados totais, com idade média de 63 anos, sendo 20 do gênero masculino e cinco do feminino. Todos eram usuários de prótese traqueoesofágica e realizaram terapia fonoaudiológica para reabilitação da comunicação traqueoesofágica. Os laringectomizados foram submetidos à avaliação da nasalância, utilizando a nasometria e avaliação perceptivo-auditiva da nasalidade, por julgamento de fonoaudiólogos treinados. Resultados: Os valores encontrados da nasalância para as frases nasais $(59,92 \%)$ e para as orais $(18,64 \%)$ estão dentro da normalidade para falantes laríngeos do português brasileiro. Foi possível perceber, na maioria dos falantes, presença de nasalidade nas frases nasais e ausência nas orais. O valor do teste de especificidade foi de $100 \%$ para as frases nasais e de sensibilidade, $100 \%$ para as frases orais. Conclusão: O laringectomizado total usuário de prótese traqueoesofágica apresenta nasalidade vocal adequada, compatível com índices nasométricos.

Study carried out at the Department of Ophthalmology, Otolaryngology and Head and Neck Surgery, School of Medicine of Ribeirão Preto, Universidade de São Paulo - USP - Ribeirão Preto (SP), Brazil.

(1) School of Medicine of Ribeirão Preto of Universidade de São Paulo - USP - Ribeirão Preto (SP), Brazil. Conflict of interests: nothing to declare.

Received: 08/09/2012 


\section{INTRODUCTION}

The effective development of alaryngeal communication after total laryngectomy is still a major challenge to the field of science and enables the social, emotional and economic reorganization of laryngectomized patients.

Tracheoesophageal voice, by the use of the tracheoesophageal prosthesis (TEP), is the form of alaryngeal communication that is closer to laryngeal voice ${ }^{(1)}$. Out of the current possibilities of vocal rehabilitation, TEP has been the method mostly accepted by specialists and laryngectomized patients, because this method allows fast learning and an effective performance of voice quality. However, despite the progress with voice proficiency and the speech of the laryngectomized patient, not all of them acquire or develop satisfactory tracheoesophageal phonation.

There is much data in published literature concerning the subjective ${ }^{(2,3)}$ and objective ${ }^{(4,5)}$ parameters of tracheoesophageal voice. Important information has been added from findings in examinations, such as esophageal manometry ${ }^{(6-8)}$ and videofluoroscopy ${ }^{(3,9,10)}$, to understand how the structures of the digestive tract and the pharyngoesophageal segment participate in the production of the tracheoesophageal sound. However, little is known about the participation of the rhinopharynx in the nasalance and nasality of the tracheoesophageal voice. Nasalance is a physical measurement that corresponds to the relative amount of acoustic energy released by the nasal cavity during speech, and nasality concerns "the subjective perception that a listener has in relation to the nasal speech component"(11).

After knowing the importance of the velopharyngeal mechanism for vocal production and based on pre-established values of nasalance for normal speakers of Brazilian Portuguese language ${ }^{(12)}$, it is essential to assess if total laryngectomized patients present nasality during the production of tracheoesophageal voice. Therefore, the objective of this study was to determine the nasalance rates of total laryngectomized patients, with tracheoesophageal voice and to correlate them with the findings in the auditory-perceptual assessment of nasality. The initial hypothesis is that nasalance rates are correlated with auditoryperceptual findings in oral and nasal sentences.

\section{METHODS}

This study was approved by the Research Ethics Committee of Hospital das Clínicas at the School of Medicine of Ribeirão Preto at Universidade de São Paulo, process HCRP n. 5.730/2011, respecting the resolution 196/96 of the National Health Council, which establishes guidelines for research, involving human beings in Brazil. Each participant signed the informed consent, expressed in specific terms for the different procedures, after being properly informed.

A total of 25 laryngectomized patients participated in this study, with a mean age of 63 years old, including male patients and five female patients. All the patients used the tracheoesophageal voice prosthesis, Provox ${ }^{\circledR}$ (Atos Medical AB, Hörby, Sweden) and underwent speech language pathology and audiology therapy for the rehabilitation of communication with TEP. Post-operative follow-up time ranged from
11 months to 14 years, with mean age of 6.38 years, and 15 patients underwent radiotherapy.

To compose the sample, medical records of total laryngectomized patients, who had undergone surgery from 1999 to 2008 , were analyzed, accounting for 258 patients. Out of these, those submitted to total laryngectomy associated or not associated to pharyngectomy were convened, as well as those speakers with primary (placement of TEP during total laryngectomy) and secondary insertion (placement of TEP after total laryngectomy), with digital occlusion of the respiratory stoma, regardless of voice quality, type of cervical leakage, with or without complementary radiotherapy.

The excluded participants were laryngectomized patients submitted to total laryngectomy associated with glossectomy, preventive or curative treatments for spasms and pharyngeal hypertonicity, that is, pharyngeal plexus neurectomy, cricopharyngeal myotomy, the chemical denervation of the pharyngeal constrictor muscle, or pharyngeal reconstruction without closing the muscle layer. Besides, those patients, who presented with recurrence or metastasis, esophageal or gastrointestinal pathologies at the time of this study were excluded, besides those complaining of dysphagia, decreased hearing accuracy and/or some type of cognitive impairment.

\section{Procedures}

All of the laryngectomized patients were submitted to a nasal video endoscopy for the assessment of velopharyngeal function. However, no laryngectomized patients presented with velopharyngeal dysfunction.

To investigate the nasalance measurements of tracheoesophageal voice, a computerized assessment was performed with the use of Nasometer II, model 6400 (KayPENTAX ${ }^{\circledR}$, New York, USA). The nasometer is equipped with a helmet and two microphones, one directed to the mouth and the other to the nose, which capture signals from nasal and oral speech components, with a horizontal plaque placed above the upper lip, separating them. The calculation of nasalance, performed in frequency rates of 300 and $600 \mathrm{~Hz}$, corresponds to the numerical ratio between nasal acoustic and total energy (sum of nasal and oral) multiplied by 100, because nasalance should be expressed with percentages. Values can range from zero, which means the absence of sound emerging through the nose, to $100 \%$, that is, sound emerging exclusively through the nose.

The nasometer was calibrated before each examination, with the sound source of the device. For the computerized analysis, mean nasalance values of the first emission of each word and sentence produced without mistakes and within the intensity limit accepted by the device were considered.

Volunteers were asked to repeat the standardized sentences into Brazilian Portuguese language ${ }^{(12)}$, being five of them, with exclusively nasal sounds and five with exclusively oral sounds, with the habitual loudness, pitch, velocity and vocal quality. The following oral sentences were used: "Papai caiu da escada" (Daddy fell off the stairs); "Fábio pegou o gelo" (Fabio took the ice"); "O palhaço chutou a bola" (The clown kicked the ball); "Tereza fez pastel" (Tereza made 
fried pie); and "A árvore dá frutos e flores" (the tree gives fruits and flowers). Nasal sentences were: "Aninha ama $o$ alemão" (Aninha loves the German); "O anão melou a mão" (the midget stained his hand"; "A lenha molhou a lama" (the wood wetted the mud); "O leão unhou o ninho" (the lion scratched the nest); and "O nenê mamou na mamãe" (the baby breastfed on mammy).

For the analysis of nasalance rates, pre-established values were considered ${ }^{(13)}$, while for the oral text, an interval lower or equal to $27 \%$ was seen as ideal. Higher values were considered as being suggestive of the presence of nasality (hypernasality). For the nasal text, the interval equal to or higher than $43 \%$ was classified as ideal, and lower values were faced as suggestive of absence of nasality (hyponasality).

In the auditory-perceptual assessment of nasality of the tracheoesophageal voice, three speech language pathologists conducted an independent judgment. All of them were voice experts, with minimum clinical experience of three years. The researcher in charge did not participate as a judge for knowing all of the laryngectomized patients. The following steps were followed for judging nasality:

- Judges training: The steps of the process were exposed, as well as the form to be filled with the response and the concept of the parameter considered, thus favoring the internal consistency of the evaluation. After the explanation, the intra-examiner calibration was performed by presenting all of the voices for them to know the emission and categorization of sentences. Afterward, the inter-examiner calibration took place and speech language pathologists discussed to get to a consensus concerning the differences recognized by ear, thus establishing the criteria aiming to reach an acceptable level of agreement in their findings of presence or absence of nasality amongst healthy adults and total laryngectomized individuals.

- Test phase: The voices were sequentially heard by the judges, with the headphone, Philips ${ }^{\circledR}$, to favor detection, selective attention, and discrimination in the analysis of stimuli. The intensity of participants' voices was adjusted to a comfortable level to the listener, remaining the same for the rest of the file. They were presented in order, first the nasal sentences and then, the oral ones. Auditory stimuli were repeated as many times as the judges thought it was necessary, and after 10 stimuli, the activity was suspended and the judge was questioned about the possibility to go on with the procedure, to prevent fatigue, lack of attention, and difficulties in auditory discrimination.

- Retest phase: To verify the intra-examiner agreement, $20 \%$ of the speech sample was presented again. The retest was conducted eight weeks later to prevent the auditory memorization of stimuli, and therefore, ensuring the reliability of the responses.

\section{Statistical analysis}

To study the responses of the auditory-perceptual assessment, sensitivity and specificity tests were used, so the positive and negative predictive values were calculated. As to the agreement analysis of the auditory-perceptual assessment of nasality, the intra-class concordance coefficient was used.

\section{RESULTS}

Among total laryngectomized patients, the mean of values found in the nasometric assessment for nasal sentences was $59.92 \%$, and for oral sentences, it was $18.64 \%$, which were within normality for laryngeal speakers of Brazilian Portuguese language (Table 1).

For nasal sentences, the auditory-perceptual assessment showed that the judges identified the nasality among most of the total laryngectomized users of TEP. In oral sentences, all of the individuals were analyzed by the judges with absent nasality (Table 2).

Table 1. Nasalance values obtained at nasometry

\begin{tabular}{lcccc}
\hline & & \multicolumn{2}{c}{ Nasalance rate (\%) } \\
\cline { 2 - 5 } & Mean & Standard deviation & Median & Minimum-maximum \\
\hline Nasal sentences & 59.9 & 10.0 & 61.0 & $32-73$ \\
Oral sentences & 18.6 & 9.8 & 16.0 & 0 \\
\hline
\end{tabular}

Table 2. Auditory-perceptual assessment of nasality according to the judgment of speech language pathologists

\begin{tabular}{lcc}
\hline & \multicolumn{2}{c}{ Auditory-perceptual assessment of nasality } \\
\cline { 2 - 4 } & Presence of nasality & Absence of nasality \\
\hline Nasal sentences & 22 & 3 \\
Oral sentences & 0 & 25 \\
\hline
\end{tabular}


In the auditory-perceptual assessment of nasal sentences, three total laryngectomized patients were evaluated by the judges as being hyponasal; however, nasalance values showed normality. Considering the nasometric assessment as the goldstandard method to identify nasality, the sensitivity and specificity of the auditory-perceptual evaluation shows the presence of absence of nasality for nasal sentences, which were $91.7 \%$ and $100.0 \%$, respectively (Table 3 ).

For oral sentences, the absence of nasality at the auditoryperceptual assessment was identified in all of the laryngectomized patients. However, nasometry values indicated six individuals with hypernasality. The sensitivity of the auditory-perceptual assessment was found to be $100 \%$ and specificity was $0 \%$ (Table 4).

\section{DISCUSSION}

For the projection of nasal sounds, it is necessary that pulmonary airflow arrives to the nasal cavity as acoustic energy during speech. Even though there is a strong relationship between measurements of nasalance and the auditory-perceptual judgment of nasality, it is important to consider that nasalance is influenced by factors, such as the impedance offered by the oral cavity and lips, as well as the permeability of the nasal cavity.

If the variables are controlled, the measurement of nasalance constitutes a useful procedure to identify resonance distortions ${ }^{(14)}$, observed by the presence of nasality during the production of oral sounds (hypernasality) and by the absence in the production of nasal sounds (hyponasality) ${ }^{(15-17)}$.

In the total laryngectomized patients, who use the TEP, the vocal tract includes fistula with TEP, esophagus, and the pharyngoesophageal segment, besides the oral and nasal cavities, which leads to increased impedance.

Nasalance values were found for laryngeal speakers, including for Brazilian Portuguese language, ranging from 12.6 to $27.0 \%$ for oral sounds and $43.0 \%$ and $43.5 \%$ for nasal sounds ${ }^{(12,18)}$.

In the study of total laryngectomized patients, for oral sentences hypernasality was considered for values equal to or higher than $27 \%$. As for nasal sentences, any percentages equal to or lower than $43 \%$ characterized hyponasality. These cut-off values maximized the sensitivity and specificity of the nasometric test to identify, respectively, the presence and the absence of the referred signals ${ }^{(13)}$. This standard was adopted, because the sample of the sentences used for the nasometric and auditory-perceptual assessments was extracted from this same reference ${ }^{(13)}$. Only oral and nasal sentences were used, because only these two stimuli are necessary to assess nasality ${ }^{(19)}$. For laryngeal speakers, nasometry is confirmedly distinct, when there is absence or presence of nasality ${ }^{(14,20,21)}$.

For total laryngectomized patients, the mean of values extracted by the nasometric analysis for nasal sentences was

Table 3. Sensitivity, specificity, positive predictive value and negative predictive value for the auditory-perceptual assessment of nasality in nasal sentences among total laryngectomized patients

\begin{tabular}{|c|c|c|}
\hline & \multicolumn{2}{|c|}{$\begin{array}{l}\text { Nasalance values obtained at nasometry } \\
\text { (gold-standard) }\end{array}$} \\
\hline & $\begin{array}{l}\text { Present nasality } \\
\quad \geq 43 \%\end{array}$ & $\begin{array}{l}\text { Absent nasality } \\
<43 \%\end{array}$ \\
\hline Presence of nasality at the auditory-perceptual evaluation & 22 & 0 \\
\hline Absence of nasality at the auditory-perceptual evaluation & 2 & 1 \\
\hline \multicolumn{3}{|l|}{ Sensitivity $=91.7 \%$} \\
\hline \multicolumn{3}{|l|}{ Specificity $=100.0 \%$} \\
\hline \multicolumn{3}{|l|}{ Positive predictive value $=100.0 \%$} \\
\hline Negative predictivevalue $=33.3 \%$ & & \\
\hline
\end{tabular}

Table 4. Sensitivity, specificity, positive predictive value and negative predictive value for the auditory-perceptual assessment of nasality in oral sentences among total laryngectomized patients

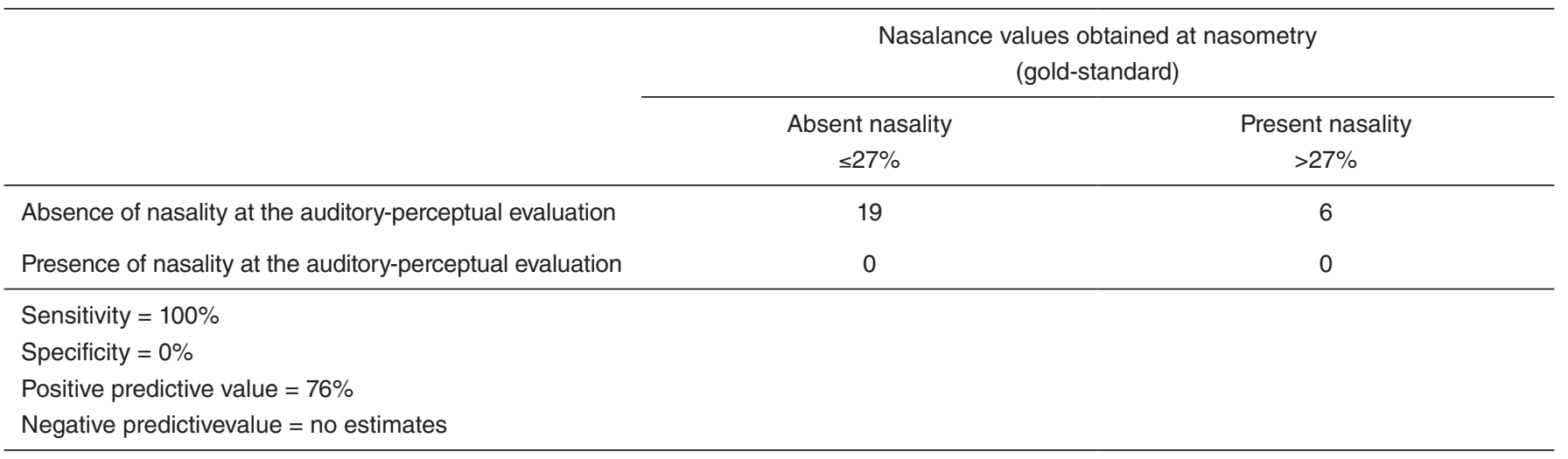


$59.92 \%$, and for oral sentences, it was $18.64 \%$. These percentages are within the limits considered as adequate for each type of sentence, considering laryngeal speakers ${ }^{(13)}$. The findings demonstrated normality for laryngeal voice; therefore, it is possible to infer that, even though the pulmonary air goes through a small orifice, such as the one of TEP, the impedance of the pathway does not prevent the amount of air to be compatible with the sufficient amount to produce nasal sounds.

In the nasalance and nasality assessment, long verbal stimuli were used, such as sentences with different phonetic contexts, allowing the increased auditory cue, because the speech sample was composed of nasal and oral sentences. However, it is possible that nasometry detects subtle resonance deflection, which are not perceptible to the human ear ${ }^{(22)}$. Maybe this is why the agreement between measurements of nasalance and perception of nasality during speech is not so consistent and strong.

By confronting the judge's opinions with nasalance rates, the experts were able to properly identify the presence and absence of nasality for most of the individuals. Only one of them was identified as a hyponasal speaker for nasal sentences by the judges and by nasometry; the others presented correspondence between the oral and nasal sentences, both for the judges and for the nasometric assessment. This finding confirms that most of the laryngectomized users of TEP were able to produce nasality, reinforcing the hypothesis that the impedance offered by the remaining vocal pathway does not prevent the amount of air to be sufficient for the production of nasal sounds. The judges got more correct answers when verifying nasality in nasal sentences, probably because it is easier to identify nasal auditory cues than oral sentences in speech ${ }^{(15)}$.

From the whole sample, in six total laryngectomized patients, it was not possible to identify the presence of nasalance during the reproduction of oral sentences, confirmed by nasometry. This finding can be associated to the fact that some of the selected sentences are composed of high pressure oral phonemes ${ }^{(23)}$, and the acoustic program could have interpreted the air flow produced by plosive phonemes as nasality, even though statistical studies did not find significant differences between nasalance and nasality scores in the sample of high-and low-pressure speech ${ }^{(24)}$. The presence of high nasalance has been observed ${ }^{(20)}$ among individuals classified by the auditory-perceptual assessment as being hyponasal, when they read nasal sentences, which was justified by the nasal air escape during the production of sentences and detected by the microphone, thus elevating nasalance scores.

However, trained listeners should be able to tell the difference between nasal escape and hypernasality. However, such justification cannot be applied to this study, because the sentences spoken by the individuals in the sample were exclusively oral.

It is important to point out that the phonetic context influences the nasalance scores ${ }^{(25)}$ of the laryngeal voice and probably, of the tracheoesophageal voice. That is why the judgments of presence or absence of nasality may not systematically accompany nasalance scores, neither is it possible to exclude the possibility of error in measurements made by nasometry, including due to contamination resulting from the acoustic transmission, which makes the combined use of auditory-perceptual assessment and nasometry essential ${ }^{(22)}$.
Concerning the differentiation between the deaf and sonorant phonemes, the time of pharyngoesophageal transitive closure of the tracheoesophageal speech, amongst the best speakers, ranges significantly between the production of phonemes /p/ and $/ \mathrm{b} /$, similarly to laryngeal speakers, and the acoustic analysis characterizes both in tracheoesophageal speech ${ }^{(26)}$. This finding demonstrates that the impedance provoked by the presence of TEP does not prevent the differentiation between deaf and sonorant phonemes, which reinforces the aforementioned hypothesis that the presence of TEP would not limit the possibility to produce nasal sounds.

The objective values extracted by nasometry cannot be used to replace the auditory-perceptual evaluation ${ }^{(27)}$, which is superior $^{(16)}$, because of the expertise of the specialist speech language pathologist. The longer the practical experience in the field of vocal resonance, the greater the ability of the professional to identify the presence and the absence, as well as the degree of nasality ${ }^{(28)}$.

The sensitivity analysis obtained by the auditory-perceptual evaluation, considering the gold-standard nasometry, revealed that judges succeeded in identifying the presence or absence of nasality in the referred sentences. The initial hypothesis that nasalance rates are correlated with auditory-perceptual findings for oral and nasal sentences was accepted after the analysis of results. This finding is important, because it confirms the previous statement that probably the impedance of the remaining vocal tract of the total laryngectomized patients does not prevent the production of perceptible nasal sounds.

Esophageal speakers presented with a velopharyngeal mechanism that is able to produce nasal sounds; however, compared to laryngeal speakers, they presented lower nasalance values ${ }^{(29)}$. The reduced nasalance of the esophageal voice can also explain why nasal consonants are not so well perceived amongst esophageal speakers. Maybe the response for the difference between the perceptive presence of nasal acoustic energy (nasalance) in form of nasality in tracheoesophageal voice and its difficult perception in esophageal voice lies exactly on the possibility of pulmonary air for the production of the tracheoesophageal voice, because this study found nasalance values of tracheoesophageal voice compatible with those of laryngeal voice, and the judges were able to identify, amongst most of the tracheoesophageal speakers, the agreement between the speech sample (nasal and oral), the auditory-perceptual analysis, and nasalance values.

For the clinical speech language pathology and audiology practice, such information suggests investments in vocal resonance techniques as part of the work to rehabilitate the voice and speech of the total laryngectomized user of TEP, because from the findings of this research, it was possible to confirm that there is enough air in the nasal and oral cavities for the increased vocal projection and the improved auditory-perceptual sensation of the speech frequency (pitch). The resonant voice promotes the easier emission and the better projection with minimum effort ${ }^{(30)}$.

The improved tracheoesophageal vocal projection may favor the maximization of speech intelligibility and tracheoesophageal voice. The possibility to improve the quality of the tracheoesophageal alaryngeal communication should reflect on the quality of life of the user, because it enables that the new voice stays closer 
to the larynx, thus decreasing the feelings of inequality and different body image among laryngectomized patients.

\section{CONCLUSION}

The total laryngectomized user of a TEP presents adequate vocal nasality, compatible with nasometric rates.

*APDI conducted data collection and tabulation, as well as the elaboration of the manuscript; HR collaborated with data collection and analysis, besides the elaboration and review of the manuscript; TKT collaborated with data analysis and the elaboration of the manuscript; NR performed data collection and analysis; LAR was in charge of the methodological study design, general orientation of the stages, and review of the manuscript.

\section{REFERENCES}

1. van As-Brooks CJ, Hilgers FJ, Koopmans-van Beinum FJ, Pols LC. Anatomical and functional correlates of voice quality in tracheoesophageal speech. J Voice. 2005;19(3):360-72.

2. Lundström E, Hammarberg B. Speech and voice after laryngectomy: perceptual and acoustical analyses of tracheoesophageal speech related to voice handicap index. Folia Phoniatr Logop. 2011;63(2): 98-108.

3. Takeshita TK, Zozolotto HC, Ribeiro EA, Ricz H, de Azevedo-Marques PM, Dantas RO, Aguiar-Ricz L. Relation between the dimensions and intraluminal pressure of the pharyngoesophageal segment and tracheoesophageal voice and speech proficiency. Head Neck. 2013;35(4):500-4.

4. Most T, Tobin Y, Mimran RC. Acoustic and perceptual characteristics of esophageal and tracheoesophageal speech production. J Commun Disord. 2000;33(2):165-80.

5. Finizia C, Dotevall H, Lundström E, Lundström J. Acoustic and perceptual evaluation of voice and speech quality: a study of patients with laryngeal cancer treated with laryngectomy vs irradiation. Arch Otolaryngol Head Neck Surg. 1999;125(2):157-63.

6. Dantas RO, Aguiar-Ricz LN, Oliveira EC, Mello-Filho FV, Mamede RC. Influence of esophageal motility on esophageal speech of laryngectomized patients. Dysphagia. 2002;17(2):121-5.

7. Aguiar-Ricz L, Dantas RO, Ricz H, Gielow I, Mamede RC, Perdoná GC. Behavior of the cricopharyngeal segment during esophageal phonation in laryngectomized patients. J Voice. 2007;21(2): 248-56.

8. Aguiar-Ricz L, Ricz H, de Mello-Filho FV, Perdoná GC, Dantas RO. Intraluminal esophageal pressures in speaking laryngectomees. Ann Otol Rhinol Laryngol. 2010;119(11):729-35.

9. Isman KA, O'Brien CJ. Videofluoroscopy of the pharyngoesophageal segment during tracheoesophageal and esophageal speech. Head Neck. 1992;14(5): 352-8.

10. Fouquet ML, Gonçalves AJ, Behlau M. Relation between videofluoroscopy of the esophagus and the quality of esophageal speech. Folia Phoniatr Lopog. 2009;61(1):29-36.
11. Fletcher SG. "Nasalance" vs. listener judgements of nasality. Cleft Palate J. 1976;13:31-44.

12. Trindade IEK, Genaro KF, Dalston RM. Nasalance scores of normal brazilian portuguese speakers. Brazil J Dysmorphol Speech Hear Disord. 1997;1:23-34

13. Trindade IE, Yamashita RP, Suguimoto RM, Mazzottini R, Trindade AS Jr. Effects of orthognathic surgery on speech and breathing of subjects with cleft and palate: acoustic and aerodynamic assessment. Cleft Palate Craniofac J. 2003;40(1):54-64.

14. Pegoraro-Krook MI, Dutka-Souza JC, Williams WN, Teles Magalhães LC, Rossetto PC, Riski JE. Effect of nasal decongestion on nasalance measures. Cleft Palate Craniofac J. 2006;43(3):289-94.

15. Di Ninno CQMS. O contraste de nasalidade em falantes normais e com fissura palatina: aspectos da produção [Tese]. Belo Horizonte: Universidade Federal de Minas Gerais; 2008.

16. Bzoch KR. A battery of clinical perceptual tests, techniques and observations for the reliable clinical assessment evaluation, and management of 11 categorical aspects of cleft palate speech disorders. In: Bzoch KR. Communicative disorders related to cleft lip and palate. Austin: Pro-ed; 2004. p. 375-462.

17. Boone DR, MacFarlane SC. Terapia para distúrbios da ressonância. In: Boone DR, MacFarlane SC. A voz e a terapia vocal. Porto Alegre: Artmed; 1994. p. 239-65.

18. Suguimoto MLCP. Pegoraro-Krook MI. Avaliação nasométrica em adultos normais falantes do português brasileiro. Pró-fono. 1995;7(2):3-9.

19. Whitehill TL. Nasalance measures in Cantonese-speaking women. Cleft Palate Craniofac J. 2001;38(2):119-25.

20. Dalston RM, Warren DW, Dalston ET. A preliminary investigation concerning the use of nasometry in identifying patients with hyponasality and/or nasal airway impairment. J Speech Hear Res. 1991;34(1):11-8.

21. Watterson T, Lewis KE, Ludlow JC, Ludlow PC. The effect of nasal decongestion on nasal patency and nasalance scores in subjects with normal speech. Cleft Palate Craniofac J. 2008;45(6):620-7.

22. Miguel HC, Genaro KF, Trindade IEK. Avaliação perceptiva e instrumental da função velofaríngea na fissura de palato submucosa assintomática. Pró-fono. 2007;19(1):105-12.

23. Bastazini SV. Nasalância na presença e ausência da turbulência nasal e da hipernasalidade [Dissertação]. Bauru: Universidade de São Paulo; 2008.

24. Watterson T, Lewis KE, Deutsch C. Nasalance and nasality in low pressure and high pressure speech. Cleft Palate Craniofac J. 1998;35(4):293-8.

25. Nellis JL, Neiman GS, Lehman JA. Comparison of Nasometer and listener judgments of nasality in the assessment of velopharyngeal function after pharyngeal flap surgery. Cleft Palate Craniofac J. 1992;29(2):157-63.

26. Saito M, Kinishi M, Amatsu M. Acoustic analyses clarify voicedvoiceless distinction in tracheoesophageal speech. Acta Otolaryngol. 2000;120(6):771-7.

27. Seaver EJ, Dalston RM, Leeper HA, Adams LE. A study of nasometric values for normal nasal resonance. J Speech Hear Res. 1991;34(4):715-21.

28. Lee A, Whitehill TL, Ciocca V. Effect of listener training on perceptual judgement of hypernasality. Clin Linguist Phon. 2009;23(5):319-34.

29. Colyar TC, Christensen JM. Nasalance patterns in esophageal speech. J Commun Disord. 1980;13(1):43-8.

30. Verdolini K, Druker DG, Palmer PM, Sawawi H. Laryngeal adduction in resonant voice. J Voice. 1998;12(3):315-27. 